\title{
Efficacy of Drivers' Fatigue on Road Accident in Selected Southwestern States of Nigeria
}

\author{
Aworemi, Joshua Remi \\ Department Of Management Science, Ladoke Akintola University of Technology \\ P.M.B. 4000, Ogbomoso, Nigeria \\ Tel: 234-803-396-7307 E-mail: Aworemi_Remi@Yahoo.Com \\ Abdul-Azeez, Ibraheem Adegoke \\ Department Of Business Administration and Management Technology, Lagos State University \\ P.M.B. 0001, Lasu Post Office Ojo, Lagos, Nigeria \\ Tel: 234-703-655-5582Ｅ-mail: Ibforson@Yahoo.Com \\ Oyedokun, Akintunde Jonathan \\ Department Of Management Science, Ladoke Akintola University of Technology \\ P.M.B. 4000, Ogbomoso, Nigeria \\ Tel: 234-803-207-0151Ｅ-mail: Aworemi_Remi@Yahoo.Com \\ Adewoye, Jonathan Oyerinde \\ Department Of Management Science, Ladoke Akintola University of Technology \\ P.M.B. 4000, Ogbomoso, Nigeria \\ Tel: 234-805-378-8888 E-mail: Aworemi_Remi@Yahoo.Com
}

\begin{abstract}
The study examines the causes and effects of driver's fatigue on road crashes in south-western Nigeria. The study was carried out in the administrative seats of Oyo and Ogun states of Nigeria with the aid of structured questionnaires which were administered on 325 respondents in the study area using simple random sampling approach. The collected data were analysed using multiple regression model.

The study revealed that, duration of driving, stress, sleep deficit, alcohol contributed significantly to the causes of driver's fatigue both at $5 \%$ and $10 \%$ significant levels.

It was concluded that, the safest option is for driver to avoid driving when sleepy on when they are ill or taking medication. And that it is pertinent on them to plan their journeys in such a way that it will include regular rest, break of at least 15 minutes at every two hours.
\end{abstract}

Keywords: Accident, Driver, Efficacy, Fatigue, Road

\section{Introduction}

The role of fatigue must not be underestimated when studying the causes of crashes. Driver fatigue crashes are not only a matter of having spent too long behind the wheel; fatigue can also be caused by too little sleep, stress, or time of the day. According to a conservative estimate based on studies abroad, driver fatigue is involved in $10-15 \%$ of all severe crashes (Nordbakke et al, 2007). Although technical aids that prevent fatigue crashes are being developed, they are not yet ready for use. In the road haulage industry, the only means that are presently available to combat fatigue crashes are consistently applying (and enforcing) the driving and resting hours and a safety culture. Information campaigns should make non-professional car drivers aware of the risks of fatigue.

The impact of driver fatigue on driving safety is a complex one. Within commercial road transport, the core issue is one of working time and the opportunity this offers for rest and recuperation from work, together with the possibility of presenting for work unimpaired by fatigue and loss of sleep. However, powerful economic and social forces influence and control the normative pattern of work of commercial drivers. Working time is, after all, one of the basic economic inputs to production and transport. Consequently, the safety argument too often has been brushed aside in the face of a commercial logic that requires flexible and on time transportation of goods and passengers, in many cases spanning the 24-hour cycle (Vanlaar et al, 2007). The customer, the consumer and new modes of production require this - and in some respects, the working conditions of many 
drivers have become harsher and more demanding over the last 30 years. For these reasons, it is of particular importance to restate the safety case for controlling more effectively the factors that give rise to fatigue.

\section{Concept of fatigue}

There is no clear definition of fatigue. The term is attributed with various meanings: physical (e.g. as a result of heavy and protracted physical labour) and neurobiological (biologically determined sleep-awake rhythms) (Nordbakke et al, 2007). In addition, it also has a mental/psychological meaning: not having the energy to do something, and a subjectively experienced reluctance to continue with a task. Fatigue, or tiredness, concerns the inability or disinclination to continue an activity, generally because the activity has been going on for "too long". There are different kinds, such as local physical fatigue (e.g. in a skeletal or ocular muscle), general physical fatigue (following heavy manual labour) or "central nervous" fatigue (sleepiness). The last of these is mental fatigue - not "having the energy" to do anything. Sleepiness is a particularly important form of fatigue related to the level of brain stimulation and the structures that regulate it ( $\AA$ kerstedt and Kecklund, 2000).

In behavioural terms, there are four levels of sleep:

(a) Completely awake

(b) Moderate sleepiness when the central nervous system maintains an adequate pattern but functions more slowly than normal (Angus and Heslegrave, 1985);

(c) Severe sleepiness, where the individual is repeatedly overcome by fatigue and Interruptions occur interactively with the surroundings and performance becomes irregular and fitful. This characterises such disorders as narcolepsy (Valley and Broughton, 1983), as well as totally healthy, but exhausted, individuals (Torsvall and Åkerstedt, 1987); and

(d) Sleep, where there is no longer any interaction with the surrounding environment.

The level of fatigue or sleepiness is a function of the amount of activity (for example, number of hours awake) in relation to the brain's physiological waking capacity. Several factors can influence this physiological waking capacity and hence lower the fatigue threshold. For example, disturbed sleep, the low point in the circadian rhythm (time of day), and alcohol and drugs. These factors are independent of the activity being undertaken, but result in the fatigue effect of that activity appearing more quickly. Thus fatigue cannot be seen simply as a function of the duration of time engaged in work (or any other activity). Furthermore, where there is a lack of sufficient restorative sleep, the fatigue threshold may be affected over a period of days or weeks.

Human beings need to sleep. Sleep is not a matter of choice; it is essential and inevitable. The longer someone remains awake, the greater the need to sleep and the more difficult it is to resist falling asleep. Sleep will eventually overpower the strongest intentions and efforts to stay awake. The need for sleep varies between individuals, but sleeping for 8 out of 24 hours is common, and 7 to 9 hours sleep is required to optimise performance. Sleep patterns are governed by the circadian rhythm (the body clock) that completes a full cycle approximately once every 24 hours.

Humans are usually awake during daylight and asleep during darkness. There are two peaks of sleepiness: the early hours of the morning and the middle of the afternoon. The loss or disruption of sleep results in sleepiness during periods when the person would usually be fully awake. The loss of even one night's sleep can lead to extreme short term sleepiness, and continual disrupted sleep can lead to chronic sleepiness. The only effective way to reduce sleepiness is to sleep. Sleeping less than four hours per night impairs performance. The effects of sleep loss are cumulative and regularly losing one or two hours of sleep a night can lead to chronic sleepiness over time.

The most comprehensive research undertaken into the effects of driver fatigue has been carried out in the USA. A series of studies by the National Transportation Safety Board (NTSB) have pointed to the significance of sleepiness as a factor in accidents involving heavy vehicles (NTSB, 1990 and 1995; Wang and Knipling, 1994). The NTSB came to the conclusion that 52 per cent of 107 one - vehicle accidents involving heavy trucks were fatigue related; in nearly 18 per cent of the cases, the driver admitted to falling asleep. In a report published by NTSB (NTSB, 1999), summarising the US Department of Transport's investigations into fatigue in the 1990s, the extent of fatigue -related fatal accidents is estimated to be around $30 \%$. Fatigue is considered the most important road safety factor for large trucks (FHWA, 1995).

In Europe, the evidence is less comprehensive, and often involves retrospective accounts of fatigue involvement which are likely to underestimate its impact. A Dutch survey found that $7 \%$ of HGV drivers attributed their accident involvement to having fallen asleep at the wheel (Van Ouwerkerk, 1987). A more recent French study 
showed that $10.5 \%$ of HGV drivers stated that fatigue had contributed to their road crash involvement (Monfrin et al, 1996). Langwieder and Sporner (1994) found that for commercial vehicles, the rate varied according to the weight of the vehicle identified as being mainly responsible for the accident: $26 \%$ for HGVs of more than 7.5 tonnes GVW and $35.7 \%$ for light vehicles under 7.5 tonnes GVW, both figures being more in line with the US results.

Posing the question in another way - what proportion of drivers report having fallen asleep at the wheel? As the results of different surveys carried out at different times show, over $50 \%$ of long -haul drivers have at some time fallen asleep at the wheel (Hamelin, 2000). While, internationally, there has been a lot of research on fatigue and safety, in Europe and Africa there have not been concerted effort to provide a strong and coherent research basis for the development of policy. Thus while quite a lot is known about the physiology of sleep and waking (particularly over cycles of no more than 24 hours) and a certain amount about the risks associated with the various parameters of working time, knowledge of the actual working hours (and how they are distributed) is limited to certain countries (Van Ouwerkerk, 1987)

\section{Causes of fatigue}

Fatigue has many causes. It used to be directly and almost exclusively associated with the amount of time that one has been carrying out a particular task (time-on-task). It is still seen as one of the most important causes. However, research has shown other factors that are equally important (Vanlaar, et al 2007). In the first place, fatigue is a lack of sleep. This can be chronic or acute.

A chronic lack of sleep is the result of not having enough sleep during a long period. The average person needs 8 hours of sleep in every 24-hour cycle. The quality of the sleep is also of great importance, besides the quantity. If sleep is regularly interrupted, this leads a chronic lack of sleep, just as too little sleep does. The quality of sleep is influenced by, among other things, sleep disorders like sleep apnoea (temporary breathing stoppage while sleeping) or narcolepsy (the tendency to suddenly fall asleep). But it can also be a side effect of chronic diseases and/or medication or the result of external factors such as a noisy or unpleasant sleeping environment (Valley and Broughton, 1983).

An acute lack of sleep is also the result of too little sleep, but is less structural than chronic lack of sleep. An acute lack of sleep can occur after just one bad or short night. If there has been too little sleep during a 24-hour period, we refer to it as a partial, acute lack of sleep. There is a complete, acute lack of sleep if there has been no sleep at all in a period of 24 hours.

Fatigue or sleepiness can also occur without lack of sleep. This type of fatigue is usually linked to the daily sleep cycle or the biorhythm. This means that at certain times in the 24-hour cycle the human body has a greater need for sleep than at other times. This happens most and lasts longest early in the morning (approximately between midnight and 4 a.m.) and, to a lesser extent, about 12 hours later (approximately between 2 p.m. and 4 p.m.). At these moments, there is a natural tendency to sleep and, if this cannot be given in to, a sleepy feeling occurs.

The duration and quality of sleep have a direct effect on the level of alertness and the ability to drive a vehicle safely. Setting off in the vehicle in the early hours of the morning means, for instance, that a person is combining driving at the low point in the circadian rhythm with a greatly shortened period of sleep. Fragmented sleep, characteristic of a sleep disorder called sleep apnoea, can in serious cases have no recuperative value whatsoever with an accompanying high risk of falling asleep at the wheel. Any cumulative sleep debt, which has built up over several days, will also adversely affect performance. Such a sleep debt needs to be dissipated over successive nights of good sleep that include the time window of the circadian low point. Some evidence suggests that following severe sleep restriction, recovery of performance may not be complete even after three nights of recovery sleep (Balkin et al, 2000).

The NTSB's in-depth study of single-vehicle accidents involving large trucks (NTSB, 1995), concluded that the most important factors behind the 58 per cent of fatigue - related accidents were the duration of the driver's last period of sleep, the total number of hours of sleep during the past 24-hour period, and fragmented sleeping patterns (several short periods of sleep). The period of sleep starts to be negatively affected if this daily rest falls below 12 to 14 hours (Kurumatani et al, 1994; Kecklund and Åkerstedt, 1995; Wylie et al, 1996; Mitler et al, 1997; Hantula, 2000).

The following factors have indirect influence: age, physical condition, the use of alcohol, drugs and/or medicine, external factors such as temperature, noise, vibrations, and also the routine of a task. For example, driving alone on a boring road for a long time may not itself cause fatigue or sleepiness, but it can cause the consequences to manifest sooner. 


\section{General effect of fatigue}

Fatigue leads to a reduction in alertness, longer reaction times, memory problems, poorer psychometric coordination, and less efficient information processing. Fatigue also has an effect on the frame of mind. The motivation to carry out a task diminishes, the communication and interaction with the surroundings deteriorates, and one gets irritated quicker and reacts more aggressively towards people and things. In other words, fatigue leads to diminished action capability and action preparedness (Langois et al, 1985; Lavie et al, 1987; Horne and Reyner, 1995; Pack et al, 1995; Hantula, 2000).

All the above-mentioned functions are important for carrying out the driving task accurately and safely. It can, therefore, be expected that fatigue also leads to a worsening of carrying out the driving task. Various studies have indeed shown this to be the case. Such research generally involves a driving simulator in which subjects either drive a long distance or are not allowed to sleep for a long time. The results of this type of study are reasonably uniform. In the first place it was found that tired people have more problems in keeping their lane, more often cross or nearly cross the side marking, and make greater steering adjustments and do so more abruptly. The drivers also react less accurately to deceleration by the driver in front (Wang, 1995).

In spite of this, the car driver appears to be capable of adjusting to the circumstances. For example, it has been found that the task performance deteriorates less when the task gets more difficult or more dangerous, for example in road bends, when an oncoming vehicle approaches, or when a vehicle in front suddenly brakes. In addition, there are also indications that a driver compensates fatigue. Initially, this is done by increasing the task demands by, for example, driving faster. Next, as fatigue increases, the task demands are decreased by driving slower and keeping a longer distance to the vehicle ahead. It must however be observed that people in a hurry use compensation in the form of lower task demands much less frequently.

\section{Fatigue and road crashes}

Fatigue is not normally referred to on road accident report forms. This means that, in general, no reliable official statistics exist for the frequency of fatigue-related road accidents. The data that do exist mostly originate from studies that estimate the extent of fatigue from other variables (for example, characteristics of accidents), or from specially constructed studies collecting new material on the incidence of tiredness in relation to accidents. Thus, while the typical representation of fatigue in official road accident statistics may be around 3\% or less (slightly more for fatal accidents), the actual contribution of fatigue is hidden by systematic under-reporting. This is demonstrated in a wide range of reliable studies, a few of which are mentioned below.

In a UK survey, "tiredness" was reported by the drivers questioned as being a factor in $7.3 \%$ of the accidents they had been involved in during the three years preceding the study (Maycock, 1995). This figure is similar to a German study (7\%) although this work focused on lorry and bus drivers (Garo et al, 1997). A Bavarian study found that $24 \%$ of the fatal accidents (irrespective of road users categories) that had occurred on motorways in 1991 (204 in total) were the result of sleepiness at the wheel (Langwieder and Sporner, 1994).

A later UK study found that sleep-related accidents accounted for $16 \%$ of all vehicle accidents occurring in Devon and Cornwall counties between 1987 and 1992 and 23\% of all accidents to which the Midlands counties police forces were called (Horne and Reyner 1995). In Australia, VicRoads, an Australian road safety organisation, estimates that $25 \%-35 \%$

(And possibly up to 50\%) of road crashes are sleep related. Fell (1994), estimated that driver sleepiness accounts for $6 \%$ of road accidents, $15 \%$ of fatal accidents and $30 \%$ of fatal crashes on rural roads. Also in Germany, a study of motorway accidents in Bavaria estimated that $35 \%$ of fatal motorway crashes were due to reduce vigilance (driver inattention and fatigue) (Hell et al, 1997). In New Zealand between 1996 and 1998, 114 fatal road crashes ( $8 \%$ of all fatal crashes) and injury road crashes (5\% of injury accidents) were thought to be fatigue related (Land Transport Safety Authority, 1998). A study of 370 heavy motor vehicle crashes in 1997, found that driver fatigue was listed as a contributing factor in $7 \%$ of accidents (Gander, et al 1998).

A questionnaire survey of 9,200 accident-involved drivers in Norway found that $3.9 \%$ of the accidents were sleep related, but almost $20 \%$ of night-time accidents involved driver drowsiness (Sagberg, 1999). An assessment of road accidents between 1984 and 1989 in Israel found that up to 1\% were recorded as sleep related, but the real figure was likely to be much higher as many accidents recorded as other types of driver error were likely to have been related to driver fatigue. In Ghana, the questionnaire survey of 250 drivers in some selected motor park in Accra revealed that 10-20\% of all single accidents are caused by fatigue (NRSC, 2008).

\section{Methodology}

The research was carried out in the administrative seats of selected states of Southwestern Nigeria (Ibadan and Abeokuta), with the aid of structured questionnaire and interview techniques. 
The states are known to have existed over the centuries as economic and administrative centres of the former kingdoms in this part of the country. The activities of the colonial administration in the mid $20^{\text {th }}$ century reinforce their growth and development (Aworemi, 2008). The states are well connected to the major cities by express roads and their locations in the country make them accessible to the more economically developed regions in the country.

The data on which the study is based were collected from a total of 325 out of 400 respondents' drivers in the study area, representing $81.25 \%$ respondent rate using simple random sampling technique. The collected data were analysed using multiple regression model. The model was chosen because it allows for dummy variables to be included. A number of fatigue related variables could not be measured or calibrated at interval, ratio or continuous scales, but in binary or dichotomous forms, therefore the inclusion of dummy will make sure that the estimates do not lose any of their properties.

The identified variables include; duration of driving, sleep deficit, experience, alcohol, stress, family responsibilities, time of the day.

The model is specified as $Y_{i}=a_{0}+b_{1} x_{1}+b_{2} x_{2}+b_{3} x_{3} \ldots \ldots \ldots \ldots \ldots+b_{n} x_{n}+U e$

Where,

$\mathrm{a}_{0}=$ Constant

$\mathrm{Y}=$ Dependent variable (fatigue)

$\mathrm{X}_{1}=$ Duration of driving

$\mathrm{X}_{2}=$ Sleep deficit

$\mathrm{X}_{3}=$ Stress

$\mathrm{X}_{4}=$ Time of the day

$\mathrm{X}_{5}=$ Age and experience

$\mathrm{X}_{6}=$ Family responsibilities

$\mathrm{X}_{7}=$ Alcohol

And $b i=b_{1} b_{2}, b_{3} \ldots$ represent the coefficient of the identified predictors

$\mathrm{Ue}=$ Error term

\section{Results and Discussion}

In attempt to analyse the efficacy of fatigue in road traffic accident, three functional forms were employed in the regression analysis. The result for each functional form is as shown in Table 1. The functional forms that were considered before choosing the lead equation were linear, semi-log and double log functions. The importance of Multiple Regression in this study is to determine how the exploratory variables $\left(\mathrm{X}_{1}-\mathrm{X}_{7}\right)$ affect the dependent variable (Y). From the three functional forms used for the data, the linear function was chosen as the lead equation. This was based on the appropriateness of the signs on the regression coefficient as specified by a priori expectation, the value of the coefficient of multiple determination $\mathrm{R}^{2}$, the number of statistically significant variables that is ' $\mathrm{t}$ ' and $\mathrm{F}$-values and tests.

The equation obtained from linear function regression result is as follows:

$\mathrm{Y}=-14.238+1.11 \mathrm{X}_{1}+0.556 \mathrm{X}_{2}+1.499 \mathrm{X}_{3}+1.545 \mathrm{X}_{4}-0.248 \mathrm{X}_{5}-0.228 \mathrm{X}_{6}+0.923 \mathrm{X}_{7}$

The coefficient of Multiple Determination $\mathrm{R}^{2}$ of 0.78 implies that $78 \%$ of the total variation in the causes of fatigue among the drivers was explained by the independent variable. The remaining $22 \%$ not explained could be attributed to the stochastic variation.

The t-value of the coefficients $\mathrm{X}_{1}, \mathrm{X}_{2}, \mathrm{X}_{3}$, and $\mathrm{X}_{7}$ were all statistically significant at both $5 \%$ and $10 \%$ levels. This implies that duration of driving $\left(\mathrm{X}_{1}\right)$, Sleep deficit $\left(\mathrm{X}_{2}\right)$, Stress $\left(\mathrm{X}_{3}\right)$, and Alcohol $\left(\mathrm{X}_{7}\right)$ contributed significantly to the variation in the causes of drivers' fatigue.

The positive regression coefficient of $\mathrm{X}_{1}, \mathrm{X}_{2}, \mathrm{X}_{3}, \mathrm{X}_{4}$, and $\mathrm{X}_{7}$ indicate that increasing in duration of driving, sleep deficit, time of the day, stress, and alcohol in-take, will have an increasing effect on fatigue which eventually can lead to accident. While the negative regression of $\mathrm{X}_{5}$, and $\mathrm{X}_{6}$, indicate that any increase in family responsibilities and experience will lead to decrease in level of fatigue.

The duration of driving $\left(\mathrm{X}_{1}\right)$ had a coefficient of 1.11 , which implies that any one-unit increase in the driving duration would increase the fatigue level of driver by 1.11. This shows that long driving duration on 
monotonous roads, such as motorways, are more likely to result in a driver falling asleep at the wheel .Journeys that are for work purposes, especially ones involving truck drivers or company car drivers, are also a high risk type of journey because they involve long period of driving. This corroborates the earlier studies by Horne et a (1995) which confirmed that all of the sleep related accidents occurred within seven hours of the start of the journey.

The age and experience of driver $\left(\mathrm{X}_{5}\right)$ has a coefficient of -0.648 , which means that the older or more experience a driver is, the less fatigue he would experience. The belief is that driver with more than 10 years driving experience or over forty years of age have a consistently lower accident risk than their younger or less experienced counterparts. This result is in contrary to the findings of Harris et al (1972) and Hamelin (2000) that older drivers appear to be more susceptible to fatigue than their younger counterpart.

Furthermore, Stress $\left(\mathrm{X}_{3}\right)$ is an important contributory factor to fatigue in driving and it is expected to contribute positively and significantly to the drivers' fatigue. It has coefficient of 1.499 , which translates to the fact that for every one unit measure of increase in Stress, there is an increase of 1.499 in the level of fatigue experience by the driver. Also it is significant at $5 \%$ which shows that Stress contributed positively and significantly to the level of fatigue in driving.

Family responsibilities $\left(\mathrm{X}_{6}\right)$ have a coefficient of -0.640 . Thus the level of fatigue decreases by 0.640 with one unit increase in family responsibilities. The implication of this is that the more responsible a driver is, the less fatigue he would be experiencing. Because he would be taking his time in making driving decisions so as not to fall victim of accident due to the responsibilities and part he is playing in the family. This corroborates the earlier finding of Aworemi (2007) that family responsibilities and social status had significant effects on accident reduction in south-western Nigeria.

Lack of sleep or sleep deficit $\left(\mathrm{X}_{2}\right)$ on the part of drivers is an important variables and it is expected to contribute positively and significantly to the level of fatigue in driving. This variable has coefficient of 1.545 , which means that one-unit increase in sleep deficit or lack of sleep by driver would result into 1.545 increases in the level of fatigue. This is in line with the study of United State National Transport Safety Board (NTSB, 1999) which ascertained that $17 \%$ (about 1 million) of road accidents are caused by drivers' fatigue.

Meanwhile, time of the day $\left(\mathrm{X}_{4}\right)$ had coefficient of 0.732 which shows that increase in time of the day by one unit would increase the level of fatigue by 0.732 . However, this value is insignificant at both $10 \%$ and $5 \%$ confidence level.

Finally, alcohol intake $\left(\mathrm{X}_{7}\right)$ had a coefficient of 2.21 which indicate that for every single alcohol taken by the driver, there is possibility of fatigue level been increased by 2.21 , which is very significant and positively related. This is in consonance with earlier study in New York (Hamelin, 2000). Some 593 truck drivers were interviewed at rest areas on New York's interstate highways. Nearly two-thirds reported episodes of drowsy driving after taking alcohol, and almost 5\% said that they drove when drowsy on most, if not all, days after taking alcohol. Nearly half had fallen asleep at the wheel at some point in their driving career, and about one-quarter reported doing so at least once during the previous year.

\section{Conclusion and Recommendation}

Driver fatigue is a serious problem resulting in many thousands of road accidents each year. It is not currently possible to calculate the exact number of sleep related accidents because of the difficulty in detecting whether fatigue was a factor and in assessing the level of fatigue. However, research suggests that up to $20 \%$ of accidents on monotonous roads in Great Britain are fatigue related (Johnson, 1998). Research in other countries also indicates that driver fatigue is a serious problem.

The safest option is for drivers to avoid driving when sleepy, when they would normally be sleeping or when they are ill or taking medication which contradicts driving or using machinery. It is crucial that drivers plan journeys, especially long ones involving driving on motorways or other monotonous roads. Drivers should:

1) Try to ensure they are well rested, and feeling fit and healthy (and not taking alcohol), before starting long journeys.

2) Plan the journey to include regular rest breaks (a break of at least 15 minutes at least every two hours). If necessary, plan an overnight stop.

3) Avoid setting out on a long drive after having worked a full day.

4) Avoid driving into the period when they would normally be falling asleep.

5) Avoid driving in the small hours (between 2am and 6am). 
6) Be extra careful when driving after eaten a meal.

7) If feeling sleepy during a journey, stop somewhere safe, take drinks containing caffeine and take a short nap.

\section{References}

Aworemi, J. R. (2008) "An evaluation of the performance of private transport companies in selected south-western state of Nigeria”, Africa Journal of Business Management, Vol.2 (8), pp 131-137.

Åkerstedt, T. (2000) "Consensus statement: Fatigue and accidents in transport operations" Journal of Sleep Research. Vol. 9 issue 4: pp395-395

Angus, R. G. and Heslegrave, R. J. (1985). "Effects of sleep loss on sustained cognitive performance during a command and control simulation". Behaviour research methods, instruments, \& computers, Vol. 17: pp 55-67.

Balkin, T. Thome, D., Sing, H., Thomas, M., Redmond, D., Wesenten, N., Williams

J., Hall, S. and Belenky, G. (2000). "Effects of sleep schedules on commercial motor vehicle driver performance". Dept of Transport Federal Motor Carrier Safety Administration, Washington. DOT-MC-00-133.

Gander, A. E. (1998) "Investigating fatigue in truck crashes: a new approach" Road Safety Board. Vol. 1 pp 34-57.

Garo C., Kiegeland P., Frieling, E. (1997). Le lien entre la durée du travail des conducteurs routiers et la sécurité routière au sein de 1'Union européenne, (The Link between Road Drivers' Working Time and Road Safety in the EU), Institut für Arbeitswissenschaft der Universität-GH Kassel, (IfA), final report to GD 7, study contract No. B95-B2 7020-SIN 3973, Kassel, Germany.

Hamelin, P. (2000). 'The working time of professional drivers as a factor of flexibility and competitiveness in road haulage and passenger transport'. Paper to the TUTBSALTSA conference 'Working without limits? Re-organising work and reconsidering workers' health.' Brussels, 25-2.

Fell, D. (1994). "Safety Update: Problem Definition and Countermeasure Summary" Research in Fatigue, Vol.3 pp15-23.

Hantula, L. (2000). Road Safety Director, Traffic Safety Committee of Insurance Companies (VALT), Finland. Personal communication.

Harris, W., et al, (1997). 'Driver Inattention and Other Causative Factors in Fatal Highway. Crashes' Proceedings of the 41st Annual Conference of the Association for the Advancement of Automotive Medicine, Orlando, USA, November, 10-11.

Horne, J.A; and Reyner, L.A. (1995). 'Sleep related vehicle accidents' in: British Medical Journal, 310, p. 565-567.

Johnson, K. (1998). 'Put Drowsy Driving to Rest' Traffic Safety 1998/05, National Safety Council, USA.

Keckland, G. and Åkerstedt, T. (1995). "Effects of timing of shifts on sleepiness and sleep duration”, Journal of Sleep Research, 4 (suppl. 2): 47-50.

Kiegeland, P., Garo, C. and Frieling, E. (1999). The Working Conditions of HGV Drivers. European Conference of the Ministers of Transport (Eds.), Social Aspects in Road Transport,12-31. Paris

Kurumatani, N., Koda, S., Nagkagiri, S. et al. (1994). The effects of frequently rotating shiftwork on sleep and the family life of hospital nurses. Ergonomics, 37: 995-1007.

Land Transport Safety Authority. (1998). 'Fatigue and Road Accidents: Factsheet 24 Land Transport Safety Authority, PO Box 2840, Wellington, New Zealand.

Langois, P.H., Smolensky, M.H., His, B.P. and Weir, F.W. (1985). Temporal patterns of reported single-vehicle car and truck accidents in Texas, USA during 1980-1983. International, 2: 131-146.

Lavie, P., Wollman, M. and Pollack, I. (1987). Frequency of sleep related traffic accidents and hour of the day. Sleep Research, 16: 275.

Maycock, G. (1995). Driver Sleepiness as a Factor in Car and HGV Accidents, Transport Research Laboratory (TRL), Crowthorne, Berkshire, UK. New South Wales Road Safety Bureau RUS No 5.

NHTSA (2001). Drowsy driving and automobile crashes. National Highway Traffic Safety Administration NHTSA, Washington DC. 
Nordbakke, S. \& Sagberg, F. (2007). Sleepy at the wheel: Knowledge, symptoms and behaviour among car drivers. Transportation Research Part F, vol. 10, nr. 1, p. 1-10.

NTSB. (1990). Fatigue, alchohol, other drugs, and medical factors in fatal-to-the driver heavy truck crashes. National Transportation and Safety Board. Safety Study 1990, NTST/SS-90/01:

NTSB. (1995). Factors that affect fatigue in heavy truck accidents. National Transportation Safety Board. Safety Study 1995, NTSB/SS-95/01

NTSB. (1999). Evaluation of U.S. Department of Transportation Efforts in the 1990s to address operator fatigue. Safety report NTSB/SR-99/01, National Transportation Safety Board, Washington, D.C. May 1999.

Pack, A.I., Pack, A.M., Rodgman, E., Cucchiara, A., Dinges, D.F. and Schwab, C.W. (1995). Characteristics of crashes attributed to the driver having fallen asleep. Accident Analysis and Prevention 1995, 27: 769-775. Research, Policing, Education Conference, Vol. 2. 1998.

Sagberg, F. (1999). 'Road Accidents Caused by Drivers Falling Asleep' Accident Analysis and Prevention, Vol. 31 , No 6 .

Torsvall, L. and Åkerstedt, T. (1987). Sleepiness on the job: continuously measured EEG changes in train drivers. Electroencephalography and Clinical Neurophysiology, 66: 502-511.

Valley, V. and Broughton, R. (1983). The physiological (EEG) nature of drowsiness and its relation to performance deficits in narcoleptics. Electroencephalography and Clinical Neurophysiology, 55: 243-251.

Van Ouwerkerk, F. (1987). Relationships between Road Transport Working Conditions, Fatigue, Health and Traffic Safety, Traffic Research Centre, University of Groningen, Groningen, NL.

Vanlaar, W., Simpson, H., Mayhew, D. \& Robertson, R. (2007). 'Fatigued and drowsy driving: A survey of attitudes, opinions and behaviours', Journal of Safety Research, vol. 39, nr. 3, p. 303-309.

Wang, J. S. (1996). 'The Role of Driver Inattention in Crashes, New Statistics from the 1995 crashworthiness data system. Proceedings of the 40th Annual Conference of the Association for the Advancement of Automotive Medicine, Vancouver, October 7-9.

Wang, J. S. and Knipling, R. R. (1994). Single vehicle roadway departure crashes, Problem size assessment and statistical description. DOT HS 808113, US Department of Transportation.

Table 1. Result of regression analysis of causes of fatigue

\begin{tabular}{|l|l|l|l|l|l|l|l|l|l|l|}
\hline Forms of Equation & Constant & $\mathbf{X}_{\mathbf{1}}$ & $\mathbf{X}_{\mathbf{2}}$ & $\mathbf{X}_{\mathbf{3}}$ & $\mathbf{X}_{\mathbf{4}}$ & $\mathbf{X}_{\mathbf{5}}$ & $\mathbf{X}_{\mathbf{6}}$ & $\mathbf{X}_{\mathbf{7}}$ & $\mathbf{R}^{\mathbf{2}}$ & F-value \\
\hline Linear Function & -14.328 & 1.11 & 0.556 & 1.499 & 1.545 & -0.248 & -0.228 & 0.923 & 0.78 & 2.11 \\
& & $(2.61)^{*}$ & $(4.24)^{*}$ & $(3.34)$ & $(0.73)$ & $(-0.64)$ & $(-0.64)$ & $(2.21)^{*}$ & \\
\hline Semi-Log Function & 52.146 & 0.147 & 0.308 & - & -0.1388 & - & - & - & 0.48 & 3.39 \\
& & $(2.41)$ & $(5.13)^{*}$ & - & $(-2.37)$ & - & - & - & \\
\hline Double Log function & 2.692 & $\begin{array}{l}0.089 \\
(1.34)\end{array}$ & $\begin{array}{l}0.241 \\
(3.74)^{*}\end{array}$ & $\begin{array}{l}0.122 \\
(2.46)\end{array}$ & $\begin{array}{l}-0.107 \\
(-1.93)\end{array}$ & $\begin{array}{l}-0.171 \\
(-3.16)\end{array}$ & $\begin{array}{l}0.104 \\
(-2.582\end{array}$ & $\begin{array}{l}0.032 \\
(0.64)\end{array}$ & 0.62 & 2.18 \\
\hline
\end{tabular}

Source: Data Analysis, 2009

$\mathrm{t}$-value in parenthesis

*Significant at $10 \%$

**Significant at $5 \%$ 